\title{
Social Isolation, Loneliness and Their Relationships with Mental Health Status in South Korea
}

\author{
Myung Hyun Kim, Ji Hyun An, Hye Rin Lee, Seo Hyun Jeong, Soo Jin Hwang, and Jin Pyo Hong ${ }^{\bowtie}$ \\ Department of Psychiatry, Samsung Medical Center, Seoul, Republic of Korea
}

\begin{abstract}
Objective This study aims to investigate the prevalence and psychological impact of social isolation and loneliness in South Korea. Loneliness and social isolation have been regarded as a risk to both physical and mental health. However, most studies have focused on the elderly; hence, there are limited studies on the characteristics of socially isolated or lonely people considering age.

Methods A sample of 1,700 participants was selected from three major cities in South Korea. In-person interviews were conducted to evaluate loneliness, social isolation and mental health status.

Results Among the participants, the prevalence of social isolation and loneliness was $17.8 \%$ and $4.1 \%$, respectively. Males decreased the odds of loneliness (AOR 0.49,95\% CI=0.28-0.87), while increasing the odds of social isolation (AOR $1.44,95 \% \mathrm{CI}=1.12-1.86$ ) after adjusting for age and sex. Greater depressive and social phobic symptoms were associated with increased odds of loneliness and social isolation.

Conclusion Social isolation and loneliness are prevalent among Koreans and associated with depression, social phobic symptoms, and suicidality. This study provides a foundation for further research to investigate nationwide prevalence and a more in-depth analysis of loneliness and social isolation.

Psychiatry Investig 2021;18(7):652-660
\end{abstract}

Key Words Social isolation, Loneliness, Mental health, South Korea, Prevalence.

\section{INTRODUCTION}

Social relationships in human society are essential to wellbeing and are related to the maintenance of health. Social isolation, defined as an objective, quantifiable reflection of the lack of social connections or interaction, usually known as deprivation of social relationships, has a crucial effect on health status and is known as a major risk factor for mortality. ${ }^{1-3}$ However, loneliness is defined by the subjective experience of being lonely, related to dissatisfaction with the discrepancy between the desired and actual frequency of social contact. ${ }^{4}$ Both social isolation and loneliness focus on social relationships; however, social isolation is thought to be more related to number of rela-

\footnotetext{
Received: February 22, 2021 Revised: April 2, 2021

Accepted: April 12, 2021

$\triangle$ Correspondence: Jin Pyo Hong, MD, PhD

Department of Psychiatry, Samsung Medical Center, Sungkyunkwan University School of Medicine, 81 Irwon-ro, Gangnam-gu, Seoul 06351, Republic of Korea

Tel: +82-2-3410-3585, Fax: +82-2-3410-0050

E-mail: suhurhong@gmail.com

(a) This is an Open Access article distributed under the terms of the Creative Commons Attribution Non-Commercial License (https://creativecommons.org/licenses/bync/4.0) which permits unrestricted non-commercial use, distribution, and reproduction in any medium, provided the original work is properly cited.
}

tionships, while loneliness is more related to the quality of social relationships. ${ }^{2}$ Loneliness can occur regardless of the presence of social isolation, and social isolation can occur regardless of whether they feel lonely. This distinction explains that feeling lonely does not necessarily mean being alone nor does being alone mean feeling alone. ${ }^{5}$ There are multiple factors related to social isolation and loneliness. Loneliness has been associated with old age, ${ }^{6}$ living or spending time alone, financial resources, ${ }^{7}$ religion, ${ }^{8}$ and ownership of a dog or cat. ${ }^{9}$ Social isolation also has been associated not only with old age, ${ }^{10}$ living alone, but also an individual who has little contact with friends and family. ${ }^{11}$ Also, living alone, limited opportunities to participate in social activities, and limited access to services and public transport are associated with an increased risk of social isolation. ${ }^{12,13}$

A growing body of research indicates that social isolation and loneliness have both been associated with physical and mental health. ${ }^{14-17}$ Social isolation and loneliness are correlated with increased risks of coronary heart disease (CHD) and stroke. ${ }^{18}$ Furthermore, loneliness has been shown to be associated with high blood pressure, ${ }^{19}$ acceleration of physiological aging, ${ }^{20}$ and depression. ${ }^{21,22}$ Loneliness has a significant effect on different age groups; for instance, lonely adolescents have 
a higher risk of experiencing poorer psychological and somatic health across countries. ${ }^{23}$ Furthermore, older people who experience high levels of loneliness are at increased risk of becoming physically frail. ${ }^{24}$ Socially isolated individuals may suffer more psychiatric stress, such as depression, anxiety, insomnia, and suicidal thoughts and behavior. ${ }^{25-27}$ Moreover, lonely individuals may more likely be addicted to harmful health behaviors such as smoking, excess alcohol consumption, binge eating or transient sexual encounters as a psychological relief means. ${ }^{28}$

Some studies have evaluated social isolation and loneliness and their effect on mental health worldwide. Few studies have examined the prevalence and hallmark of social isolation and loneliness, and their effect on mental health in South Korea. Furthermore, these studies focus on specific age groups such as adolescents, or old age groups, which cannot explain the effect of age differences. This study aims to investigate the prevalence of social isolation and loneliness in community-dwelling participants in South Korea, their sociodemographic characteristics, and evaluate their mental health status compared to healthy participants.

\section{METHODS}

\section{Participants and procedures}

This study was conducted between 23th July and 30th August 2019. Participants were selected from three representative districts (Gangnam-gu, Seoul for metropolitan area, Pajusi, Gyeonggi-do for rural areas, Jung-gu, Daegu for mid-sized cities) in South Korea. We used a multistage, cluster sampling method based on administrative districts. We selected three catchment areas (Si/Gun/Gu in Korean) based on population size and accessibility to research centers. Next, three subdivisions (Eup/Myeon/Dong) per catchment area were randomly selected. We adopted 50 household blocks as sampling units. Every household in each unit was included in the survey, and one individual per household was randomly chosen as the respondent. The target population included community residents aged 15 to 74 years. Face-to-face interviews were performed by trained field workers who conducted preliminary surveys by visiting every household to compile a list of eligible subjects. Household visits were repeated at least five times to contact individuals who were temporarily unavailable. A total of 1,700 people participated in this study. All subjects were fully informed about the aims and methods of the study before completing the interview, and informed consent was obtained prior to participation. This study was approved by the Institutional Review Board of Samsung Medical Center (SMC 2020-05-145).

\section{Measures}

\section{Sociodemographic data}

Socio-demographic information included gender, age, marital status, education, subjective financial satisfaction, frequency of religious service attendance and self-rated health status. Age group was divided into four categorical variables (15-29, 30$44,45-59$, and 60-74 years). Marital status was classified into married, never married and separated/divorced/widowed. Education years were dichotomized into two groups with the criteria of twelve years which is a mandatory education period in South Korea. Subjective financial information was answered by four categorical variables (very satisfied, satisfied, less satisfied, and not satisfied at all). Self-rated health status was collected by three categorical variables (good, fair, and poor).

\section{Social isolation}

The Lubben Social Network Scale (LSNS) is one of the widely used instruments to assess perceived social support received from family and friends, which consists of 10 items. ${ }^{29}$ LSNS-6 is an abbreviation of LSNS to effectively screen for social isolation using six questions. ${ }^{30}$ LSNS-6 is constructed from a set of three questions that evaluate familial networks and a comparable set of three questions that evaluate non-familial networks. The items include the following: "How many relatives do you see or hear from at least once a month?, "How many relatives do you feel close to such that you could call on them for help?," "How many relatives do you feel at ease with that you can talk about private matters?." These three items are repeated by replacing the word relatives with friends. Each item is answered through 0 (no relatives/friends) to 5 ( 9 or more relatives/friends), and the sum of each item is calculated. The overall scores range from 0 to30 and participants who had an LSNS-6 score less than 12 were considered to be at risk for social isolation. ${ }^{30}$ The Lubben Social Support Network Scale-Korean version is used in Korea to assess social network among Korean population and its reliability and validity have been established. ${ }^{31}$ In this study, we used the Korean version of LSNS- 6 to assess social isolation of participants, and participants who had an LSNS- $6<12$ were designated as the social isolation group.

\section{Loneliness}

We measured loneliness with single-item loneliness questions used in the English Longitudinal Study of Ageing (ELSA), which was "How often do you feel lonely?"32 The response ranged from 1 (hardly lonely), 2 (lonely some of the time), and 3 (often lonely). Participants who answered 3 (often lonely) were designated as the loneliness group. 


\section{Mental health status}

Frequency of alcohol usage was measured by Alcohol Use Disorder Identification Test-Consumption (AUDIT-C), as $0=$ not at all, $1=$ monthly or less, $2=$ two to four times a month, $3=$ two or three times per week, $4=$ four or more times a week. ${ }^{33}$ Those who reported drinking "four or more times a week" were considered heavy drinkers. Smoking status was measured as the number of cigarettes a person smoked a day. Those who reported smoking more than one pack a day were considered heavy smokers.

The Korean version of the Patient Health Questionnaire-9 (PHQ-9) was used to screen participants' depression. ${ }^{34}$ PHQ-9 is a well-validated screening tool for depression and consists of nine questions on depression over the past two weeks. Each score of the questions ranged from 0 to 3 . The summed score over 10 is considered as clinical depression. ${ }^{35}$ To screen social anxiety disorder (SAD), we used Mini-Social Phobia Inventory (Mini-SPIN), which is the abbreviated form of Mini-Social Phobia Inventory (SPIN). ${ }^{36}$ Mini-SPIN consists of three items as following: "Fear of embarrassment causes me to avoid doing things or speaking to people," "I avoid activities in which I am the center of attention," "Being embarrassed or looking stupid are among my worst fears." Each item scores 0 to 4 , and the sum of items over 6 was considered as SAD. ${ }^{36}$

Suicidal thoughts were assessed by the suicidal chapter of the Korean version of the Composite International Diagnostic Interview (K-CIDI): "Have you ever seriously thought of suicide?" Responses were recorded as yes or no.

The participant's life satisfaction scores were measured using the Cantril Self-Anchoring scale with the question "How do you expect your present life satisfaction score?"'38 Participants were asked to assume a ladder as the top of the ladder represents the best possible life and the bottom of the ladder represents the worst possible life, and the answers were collected on an 11-point Likert scale (from $0=$ worst possible life to $10=$ best possible life). ${ }^{39}$

Preference of online social interaction (POSI) was measured using subscale of the Generalized Problematic Internet Use Scale 2 (GPIUS2).$^{40}$ POSI refers to a cognitive construct characterized by beliefs that one is safer, more confident, and more comfortable with online interactions than with face-to-face interactions. POSI consists of three questions as following: "I prefer online social interaction over face-to-face communication," "Online social interaction is more comfortable for me than faceto-face interaction," "I prefer communicating with people online rather than face-to-face." The answers were collected on an 8-point Likert scale (from $0=$ absolutely not to $10=$ highly yes) and the sum of each item is calculated. In addition, we aimed to evaluate participants' preference for solitude by asking "Do you prefer being alone rather than being together?" Participants answered the question as 1 (not at all), 2 (usually not), 3 (sometimes yes), and 4 (usually).

\section{Statistical analysis}

Our analysis focused on community-dwelling participants from three major cities in South Korea to examine the national prevalence of social isolation and loneliness. We used analytic survey weights based on the 2018 Korean Census (Korea National Statistical Office, 2018) to account for differential selection probabilities. For demographic and clinical characteristics, we used t-tests or chi-squared tests for group differences. We also performed unadjusted multinomial logistic regression to test the association between sociodemographic characteristics and mental health status as well as social isolation and loneliness. Lastly, after adjusting for sociodemographic factors, we performed a multinomial multivariable logistic regression to determine the association between sociodemographic characteristics and mental health status as well as social isolation and loneliness. All statistical analyses were performed using IBM SPSS Statistics version 20.0 (IBM Corp., Armonk, NY, USA).

\section{RESULTS}

\section{Sociodemographic characteristics of Social Isolation and Loneliness Group}

Table 1 presents the sociodemographic characteristics of all the participants in the social isolation and loneliness groups. A total of 1,700 subjects (699 males and 1,001 females) completed the interview. $4.1 \%$ of the subjects reported they were often lonely ( $\mathrm{n}=63$ ), and $17.8 \%$ of the subjects reported that they were socially isolated $(\mathrm{n}=295)$. Loneliness was more frequent in females ( $74.6 \%$ vs. $58.9 \%, \mathrm{p}=0.009$ ), while social isolation was more frequent in males ( $48.5 \%$ vs. $41.1 \%, \mathrm{p}=0.005$ ). There was no statistical age difference between the reference group and loneliness group, whereas age groups of 30-44 years and 60-74 years reported more social isolation than the reference group. The loneliness group was more likely to be widowed/separated/divorced (19.0\% vs. $6.1 \%, \mathrm{p}=0.000)$ and less educated ( $63.5 \%$ vs. $45.5 \%, \mathrm{p}=0.004)$ compared to the reference group. However, there was no statistical difference in marital status and education years between the social isolation and reference groups. Both loneliness and social isolation groups were more likely to be economically unstable than reference group, responding "Less satisfied (32.8\% in loneliness group, $29.2 \%$ in social isolation group)" and "Not satisfied at all" (39.1\% in loneliness group, $19.0 \%$ in social isolation group)" more than reference group, which is statistically significant $(\mathrm{p}<0.05)$. Furthermore, most participants reported their self-rated health as "poor" in both loneliness and social isolation groups (47.6\% in loneliness group, $28.6 \%$ in social isolation group, $\mathrm{p}<0.001)$. 
Table 1. Sociodemographic characteristics of social isolation and loneliness group

\begin{tabular}{|c|c|c|c|c|c|}
\hline & Total $(\mathrm{N}=1,700)$ & Social isolation group $(\mathrm{N}=295)$ & $\mathrm{p}$ & Loneliness group $(\mathrm{N}=63)$ & $\mathrm{p}$ \\
\hline \multicolumn{6}{|l|}{$\operatorname{Sex}(N, \%)$} \\
\hline Female (ref) & $1,001(58.9)$ & $152(51.5)$ & - & $47(74.6)$ & - \\
\hline Male & $699(41.1)$ & $143(48.5)$ & 0.005 & $16(25.4)$ & 0.009 \\
\hline \multicolumn{6}{|l|}{ Age group $(\mathrm{N}, \%)$} \\
\hline $15-29$ (ref) & $395(23.2)$ & $49(16.6)$ & - & $16(25.4)$ & - \\
\hline $30-44$ & $460(27.1)$ & $101(34.1)$ & $<0.001$ & $12(19.0)$ & 0.161 \\
\hline $45-59$ & $531(31.2)$ & $91(30.7)$ & 0.028 & $18(28.6)$ & 0.360 \\
\hline $60-74$ & $315(18.5)$ & $55(18.6)$ & 0.037 & $17(27.0)$ & 0.249 \\
\hline \multicolumn{6}{|l|}{ Marital status (N, \%) } \\
\hline Married (ref) & $1,160(68.2)$ & $201(67.9)$ & - & $32(50.8)$ & - \\
\hline Never married & $437(25.7)$ & $71(24.0)$ & 0.654 & $19(30.2)$ & 0.111 \\
\hline Separated/divorced/widowed & $104(6.1)$ & $24(8.1)$ & 0.139 & $12(19.0)$ & $<0.001$ \\
\hline \multicolumn{6}{|l|}{ Education (years) (N, \%) } \\
\hline 12 or less (ref) & $757(45.5)$ & $135(46.2)$ & - & $40(63.5)$ & - \\
\hline More than 13 & $909(54.5)$ & $157(53.8)$ & 0.796 & $23(36.5)$ & 0.004 \\
\hline \multicolumn{6}{|l|}{ Financial satisfaction $(\mathrm{N}, \%)$} \\
\hline Pretty well satisfied (ref) & $514(30.3)$ & $54(18.3)$ & - & $9(14.1)$ & - \\
\hline Satisfied & $642(37.9)$ & $99(33.6)$ & 0.018 & $9(14.1)$ & 0.641 \\
\hline Less satisfied & $392(23.1)$ & $86(29.2)$ & $<0.001$ & $21(32.8)$ & 0.004 \\
\hline Not satisfied at all & $147(8.7)$ & $56(19.0)$ & $<0.001$ & $25(39.1)$ & $<0.001$ \\
\hline \multicolumn{6}{|c|}{ Frequency of religious service attendance $(\mathrm{N}, \%)$} \\
\hline Never (ref) & $134(13.9)$ & $27(17.4)$ & - & $4(11.4)$ & - \\
\hline 1 time per week or less & $388(40.2)$ & $58(37.4)$ & 0.173 & $17(48.6)$ & 0.614 \\
\hline More than 1 time per week & $444(46.0)$ & $70(45.2)$ & 0.234 & $14(40.0)$ & $>0.999$ \\
\hline \multicolumn{6}{|l|}{ Self-rated health (N, \%) } \\
\hline Good (ref) & $670(39.7)$ & $86(29.7)$ & - & $10(15.9)$ & - \\
\hline Fair & $735(43.6)$ & $121(41.7)$ & 0.060 & $23(36.5)$ & 0.052 \\
\hline Poor & 282(16.7) & $83(28.6)$ & $<0.001$ & $63(47.6)$ & $<0.001$ \\
\hline
\end{tabular}

Neither group showed statistical differences in the frequency of religious service attendance.

\section{Comparison of mental health status among social isolation group and loneliness group}

Table 2 presents comparison of heal behaviors and mental health status among social isolation and loneliness groups. Concerning health behaviors, both social isolation and loneliness groups were more likely to be heavy smokers. Suicidal thoughts were significantly more in both groups ( $19.7 \%$ for social isolation group and 52.4\% for loneliness group); moreover, even it was reported about five times more in group with loneliness than the group without $(11.3 \%, \mathrm{p}<0.000)$ About $39 \%$ of the loneliness group and $13 \%$ of the social isolation group reported depressive symptoms, scored ten or more in PHQ-9, which were statistically higher than reference group $(\mathrm{p}=0.000)$. Also, both social isolation (35.9\%) and loneliness (52.4\%) groups reported more social anxiety symptoms, scored 6 or more in Mini$\operatorname{SPIN}(\mathrm{p}<0.000)$.

\section{Unadjusted and adjusted odds ratio of social isolation and loneliness with sociodemographic characteristics, health behaviors and mental health status}

Associations between social isolation, loneliness, sociodemographic variables, health behavior, and mental health status are presented in Table 3. Model 1 was adjusted for only gender and age, while model 2 included all variables using multivariate logistric regression analysis. Males were significantly associated with social isolation in both model 1 (AOR 1.44, 95\% $\mathrm{CI}=1.12-1.86$ ) and model 2 (AOR 1.85, 95\% CI=1.37-2.50). Males were associated with a decreased risk of loneliness in model 1 (AOR 0.49, 95\% CI=0.28-0.87), but the effect was not 
Table 2. Comparison of mental health status among social isolation group and loneliness group

\begin{tabular}{|c|c|c|c|c|c|c|}
\hline & \multicolumn{3}{|c|}{ Social isolation group } & \multicolumn{3}{|c|}{ Loneliness group } \\
\hline & No $(N=1,405)$ & Yes $(\mathrm{N}=295)$ & $\mathrm{p}$ & No $(N=1,637)$ & Yes $(\mathrm{N}=63)$ & $\mathrm{p}$ \\
\hline \multicolumn{7}{|l|}{ Frequent alcohol use (N, \%) } \\
\hline More than 4 times per week & $58(4.1)$ & $16(5.4)$ & 0.345 & $69(4.2)$ & $5(7.8)$ & 0.197 \\
\hline \multicolumn{7}{|l|}{ Usage of Tobacco (N, \%) } \\
\hline More than 1 pack per day & $44(3.2)$ & $22(7.7)$ & 0.001 & $59(3.7)$ & $7(11.3)$ & 0.010 \\
\hline \multicolumn{7}{|l|}{ Suicidal thought (N, \%) } \\
\hline Yes & $158(11.3)$ & $58(19.7)$ & $<0.001$ & $184(11.3)$ & $33(52.4)$ & $<0.001$ \\
\hline \multicolumn{7}{|l|}{ Depression (N, \%) } \\
\hline Yes & $42(3.0)$ & $38(12.9)$ & $<0.001$ & $57(3.5)$ & $25(39.1)$ & $<0.001$ \\
\hline \multicolumn{7}{|l|}{ Social phobia (N, \%) } \\
\hline Yes & $213(15.2)$ & $106(35.9)$ & $<0.001$ & $286(17.5)$ & $33(52.4)$ & $<0.001$ \\
\hline Present life satisfaction score $(\mathrm{M}, \mathrm{SD})$ & $6.24(1.74)$ & $5.23(1.93)$ & $<0.001$ & $6.15(1.76)$ & $4.02(2.17)$ & $<0.001$ \\
\hline Preference of online social interaction (M, SD) & $9.11(4.72)$ & $9.47(5.10)$ & 0.269 & $9.18(4.78)$ & $8.85(4.95)$ & 0.584 \\
\hline
\end{tabular}

Depression: PHQ-9 $\geq 10$; Social phobia: Mini-SPIN $\geq 6$. PHQ-9: Patient Health Questionnaire-9, Mini-SPIN: Mini-Social Phobia Inventory

significant in model 2 (AOR 0.46, 95\% CI=0.21-1.01). Compared to the youngest age group, the older age group tended to increase the odds of social isolation. In particular, the youngmid-age group (30-44 years) was associated with nearly three times as high odds of social isolation (AOR 2.61, 95\% CI=1.524.48). Financially unsatisfied and poor level of self-rated health were significantly associated with higher odds of both social isolation and loneliness. Heavy smoking increased the odds of both social isolation and loneliness in model 1 , but not in model 2.

As expected, experiencing depression was also strongly associated with social isolation and loneliness. The presence of depressive symptoms increased the odds of loneliness by about 18 times in model 1 (AOR 17.07, 95\% CI=9.62-30.28), which decreased to 3 times in model 2 ( $\mathrm{AOR} 3.42,95 \% \mathrm{CI}=1.61-7.26$ ), but was still statistically significant. Participants with social anxiety symptoms were also more likely to experience social isolation (AOR 2.74, 95\% CI=2.01-3.75) and loneliness (AOR 3.06, $95 \% \mathrm{CI}=1.65-5.68$ ) with similar effects. Suicidal thoughts were significantly associated with loneliness in both model 1 (AOR 8.23, 95\% CI=4.89-13.87) and model 2 (AOR 4.21, 95\% CI= 2.21-8.02). For social isolation, suicidal thoughts increased the odds in model 1 (AOR 2.07, 95\% CI=1.48-2.90), but not in model 2 (AOR 1.22, 95\% CI=0.82-1.83).

\section{DISCUSSION}

This study is the first to investigate the prevalence of social isolation and loneliness and its association with sociodemographic characteristics and different health behaviors and mental health status among a community sample of 1,700 participants in South Korea. This study is meaningful as it tried to include a diverse range of age groups from early to late adulthood (15 to 74 years), contrary to previous studies that were limited to old age or adolescents. After adjusting for sociodemographic variables, social isolation and loneliness were strongly associated with depressive symptoms, social anxiety symptoms, and suicidal thoughts.

The prevalence of social isolation was $17.8 \%$ for study participants, which was lower than previous research results $(24.1 \%$ to $38.85 \%),{ }^{41,42}$ probably because our research included a wide range of age groups, including early adulthood from 15 to 29 years of age compared to previous research which focused in older adults. Among participants, male gender, less financial satisfaction, and poor level of self-rated health were associated with social isolation, which is consistent with previous research. ${ }^{43,44}$ Although few studies have found no gender difference in social isolation, ${ }^{43,45}$ our findings support that males were strongly associated with social isolation, probably because they have a tendency to report less social contact with friends or family than females. ${ }^{46}$ The age group 30-44 years showed the highest rate of social isolation. Previous research has shown that young adults desire a greater number of social networks on average and report more social isolation than older adults, ${ }^{47}$ which concurs with our results. While older adults may join social groups for enrichment, or to fulfill engagement, young adults may join these groups for networking opportunities to meet and interact with peers. ${ }^{47}$ Our findings would seem to show that young adults, particularly 30-44 years, have less opportunities to engage in social communications with their family or friends than older adults. These findings can be explained in part by the rise of single-person households in South Korea, especially in younger adults either voluntarily or circumstantially. Also, social interaction of younger adults might be fo- 
MH Kim et al.

Table 3. Unadjusted and adjusted odds ratio of social isolation and loneliness with sociodemographic characteristics and mental health status

\begin{tabular}{|c|c|c|c|c|}
\hline & \multicolumn{4}{|c|}{ OR $(95 \% \mathrm{CI})$} \\
\hline & \multicolumn{2}{|c|}{ Social isolation group $(\mathrm{N}=295)$} & \multicolumn{2}{|c|}{ Loneliness group $(\mathrm{N}=63)$} \\
\hline & Model 1 & Model 2 & Model 1 & Model 2 \\
\hline \multicolumn{5}{|l|}{ Sex } \\
\hline Female & 1.00 & 1.00 & 1.00 & 1.00 \\
\hline Male & $1.44(1.12,1.86)^{\dagger}$ & $1.85(1.37,2.50)^{\dagger}$ & $0.49(0.28,0.87)^{*}$ & $0.46(0.21,1.01)$ \\
\hline \multicolumn{5}{|l|}{ Age group } \\
\hline $15-29$ & 1.00 & 1.00 & 1.00 & 1.00 \\
\hline $30-44$ & $1.99(1.37,2.89)^{\dagger}$ & $2.61(1.52,4.48)^{\dagger}$ & $0.61(0.29,1.30)$ & $1.00(0.33,3.07)$ \\
\hline $45-59$ & $1.46(1.00,2.13)^{*}$ & $2.02(1.13,3.61)^{*}$ & $0.81(0.41,1.59)$ & $0.90(0.28,2.88)$ \\
\hline $60-74$ & $1.49(0.98,2.26)$ & $2.01(1.08,3.74)^{*}$ & $1.34(0.67,2.68)$ & $1.24(0.37,4.21)$ \\
\hline \multicolumn{5}{|l|}{ Marital status } \\
\hline Married & 1.00 & 1.00 & 1.00 & 1.00 \\
\hline Never married & $1.02(0.68,1.52)$ & $1.26(0.77,2.08)$ & $2.55(1.16,5.62)^{*}$ & $1.00(0.36,2.82)$ \\
\hline Separated/divorced/widowed & $1.55(0.95,2.51)$ & $1.56(0.89,2.73)$ & $4.22(2.08,8.54)^{\dagger}$ & $2.07(0.84,5.12)$ \\
\hline \multicolumn{5}{|l|}{ Education (years) } \\
\hline 12 or less & 1.00 & 1.00 & 1.00 & 1.00 \\
\hline More than 13 & $0.95(0.73,1.24)$ & $0.88(0.65,1.21)$ & $0.48(0.28,0.82)^{\dagger}$ & $0.54(0.27,1.06)$ \\
\hline \multicolumn{5}{|l|}{ Financial satisfaction } \\
\hline Pretty well satisfied & 1.00 & 1.00 & 1.00 & 1.00 \\
\hline Satisfied & $1.55(1.08,2.21)^{*}$ & $1.45(0.99,2.12)$ & $0.78(0.30,2.00)$ & $0.52(0.18,1.48)$ \\
\hline Less satisfied & $2.48(1.71,3.59)^{\dagger}$ & $1.83(1.21,2.75)^{\dagger}$ & $3.26(1.47,7.23)^{\dagger}$ & $1.41(0.56,3.60)$ \\
\hline Not satisfied at all & $5.27(3.39,8.18)^{\dagger}$ & $3.52(2.12,5.84)^{\dagger}$ & $12.49(5.62,27.76)^{\dagger}$ & $4.43(1.68,11.67)^{\dagger}$ \\
\hline \multicolumn{5}{|l|}{ Self-rated health } \\
\hline Good & 1.00 & 1.00 & 1.00 & 1.00 \\
\hline Fair & $1.39(1.03,1.89)^{*}$ & $1.25(0.90,1.73)$ & $2.04(0.96,4.37)$ & $1.22(0.53,2.80)$ \\
\hline Poor & $3.04(2.14,4.30)^{\dagger}$ & $1.85(1.24,2.75)^{\dagger}$ & $7.42(3.54,15.55)^{\dagger}$ & $2.67(1.14,6.27)^{*}$ \\
\hline \multicolumn{5}{|l|}{ Frequency of alcohol use } \\
\hline 3 times or less per week & 1.00 & 1.00 & 1.00 & 1.00 \\
\hline More than 4 times per week & $1.19(0.67,2.12)$ & $0.83(0.44,1.57)$ & $2.19(0.84,5.72)$ & $1.30(0.39,4.36)$ \\
\hline \multicolumn{5}{|l|}{ Usage of Tobacco } \\
\hline Less than 1 pack per day & 1.00 & 1.00 & 1.00 & 1.00 \\
\hline More than 1 pack per day & $2.02(1.17,3.51)^{*}$ & $1.43(0.76,2.69)$ & $7.74(2.87,20.90)^{\dagger}$ & $2.96(0.85,10.33)$ \\
\hline \multicolumn{5}{|l|}{ Suicidal thought } \\
\hline No & 1.00 & 1.00 & 1.00 & 1.00 \\
\hline Yes & $2.07(1.48,2.90)^{\dagger}$ & $1.22(0.82,1.83)$ & $8.23(4.89,13.87)^{\dagger}$ & $4.21(2.21,8.02)^{\dagger}$ \\
\hline \multicolumn{5}{|l|}{ Depression } \\
\hline No & 1.00 & 1.00 & 1.00 & 1.00 \\
\hline Yes & $5.15(3.24,8.17)^{\dagger}$ & $2.28(1.30,4.02)^{\dagger}$ & $17.07(9.62,30.28)^{\dagger}$ & $3.42(1.61,7.26)^{\dagger}$ \\
\hline \multicolumn{5}{|l|}{ Social phobia } \\
\hline No & 1.00 & 1.00 & 1.00 & 1.00 \\
\hline Yes & $3.37(2.53,4.47)^{\dagger}$ & $2.74(2.01,3.75)^{\dagger}$ & $5.25(3.14,8.80)^{\dagger}$ & $3.06(1.65,5.68)^{\dagger}$ \\
\hline
\end{tabular}

Depression: PHQ-9 $\geq 10$; Social phobia: Mini-SPIN $\geq 6$. Model 1 was adjusted for only gender and age. Model 2 included all variables/model 1: univariate logistic regression (adjusted for only gender and age), model 2 : multivariate logistic regression. ${ }^{*} \mathrm{p}<0.05$, ${ }^{\dagger} \mathrm{p}<0.01$. OR: odds ratio, CI: confidence interval, PHQ-9: Patient Health Questionnaire-9, Mini-SPIN: Mini-Social Phobia Inventory 
cused to their coworkers or colleague, which do not correspond with friend or relative category. Further studies are needed to explore the characteristics of social isolation in young adults. Furthermore, another study showed that social isolation is associated with older age, due to reduced social connect and physical inconvenience. ${ }^{48}$ Therefore, a growing body of study focuses engaging older adults to social interventions. In Japan, a 3-year longitudinal study showed that participation in social activities reduces future social isolation in older people. ${ }^{49}$ Therefore, future social engagement programs such as community services, senior clubs, hobbies, volunteering, and religious activities is needed for socially isolated people to improve their physical and mental health.

The prevalence of loneliness was $4.1 \%$ among the study participants. In England, the prevalence of loneliness reported by ELSA over the age 50 years was 6-8\% from 2006 to $2016,{ }^{32}$ which was higher than our result which covers wide range of age groups. Our result revealed that older adults reported more that they were lonely than younger adults, which is consistent with previous results that old age is associated with loneliness. ${ }^{620,47} \mathrm{Fe}$ males were strongly associated with loneliness, which corresponds with numerous previous studies. ${ }^{32.50}$ Separated/divorced/ widowed status, less educated, financial dissatisfaction and poor self-rated health status were also associated with loneliness in participants. Unlike previous results, the frequency of religious service attendance was unrelated to loneliness and social isolation.

Both social isolation and loneliness were clearly associated with mental health status, such as suicidal thoughts, depressive symptoms and social anxiety symptoms. Further, $52.4 \%$ of the participants who felt lonely reported that they had suicidal ideation, which was nearly five times more than the non-loneliness group, which is higher than pervious results (11.69\% to $41.8 \%)^{51,52}$ The proportion of participants with depressive and social anxiety symptoms was higher in the loneliness group than in the social isolation group. In previous research, loneliness was associated with depressive symptoms and its' relationship was stronger than that of social isolation and depressive symptoms. ${ }^{50}$ Since loneliness is more perceived, subjective emotion of "being alone," this seems to have a greater impact on an individual's mood, such as depression or anxiety and vice versa. In addition, loneliness is a mediator in the relationship between social engagement and depressive symptoms. ${ }^{53}$ Moreover, both social isolation group and loneliness group answered their present life satisfaction score lower than non-social isolation group and non-loneliness group, respectively. Pessimistic views of the present or the future is an important component in depressive symptoms, suggesting that both social isolation and loneliness have higher impact on depressive symptoms in participants. Interestingly, the mean score of preference of online social interaction (POSI) had no significant difference be- tween social isolation and non-social isolation group. Also, there was no statistical difference in mean score of POSI between loneliness and loneliness group. This result was contrary to what we have expected, that socially isolated, lonely people prefer online communication, to avoid immediate face-to-face relationship and to enjoy the anonymity of online communication. A reasonable explanation for this result may be that socially isolated, lonely individuals have a similar desire for face-to-face social interaction with others.

Several limitations of this study need to be discussed. First, we conducted a cross-sectional analysis aimed at identifying the prevalence and correlation of social isolation and loneliness among participants but were not able to test causality or longitudinal changes. Second, since the survey was conducted in three major cities in South Korea, sampling might not be representative of South Korea's population. Third, underestimation of social isolation and loneliness could occur due to the unresponsiveness of truly socially isolated or lonely people. Moreover, psychiatric evaluation of participants was only assessed by a questionnaire, not by the clinician's interview. To accurately explore the mental health status of people who are socially isolated or lonely, further in-depth psychiatric examinations are needed.

This study is the first to investigate the prevalence of social isolation and loneliness among community-dwelling participants and their health behavior and mental health status in South Korea This study is meaningful as it tried to include a diverse range of age groups contrary to previous studies that were limited to old age or adolescents. Male gender, financial dissatisfaction, and poor self-rated health were associated with social isolation. Also, female gender, non-marital status, less educated, financial dissatisfaction and poor self-rated health status were also associated with loneliness in participants. After adjusting for sociodemographic variables, social isolation and loneliness were strongly associated with depressive symptoms, social anxiety symptoms and suicidal thoughts. This study informs the actual state of social isolation and loneliness and offers useful resources for public health policy makers to establish governmental intervention and mental health care support.

\section{Acknowledgments}

This work was supported by the Korea Healthcare Technology R\&D project, Ministry of Health and Welfare, Republic of Korea (HL19C0018).

\section{Conflicts of Interest}

The authors have no potential conflicts of interest to disclose.

\section{Author Contributions}

Conceptualization: Jin Pyo Hong, Ji Hyun An. Data curation: Soo Jin Hwang, Myung Hyun Kim. Formal analysis: Myung Hyun Kim, Ji Hyun An. Funding acquisition: Jin Pyo Hong. Investigation: Myung Hyun Kim, Ji Hyun An. Methodology: Jin Pyo Hong, Soo Jin Hwang. Project adminis- 
tration: Jin Pyo Hong, Ji Hyun An. Supervision: Jin Pyo Hong. Writingoriginal draft: Myung Hyun Kim, Hye Rin Lee, Seo Hyun Jeong, Soo Jin Hwang. Writing_-review \& editing: Jin Pyo Hong, Ji Hyun An.

\section{ORCID iDs}

$\begin{array}{ll}\text { Myung Hyun Kim } & \text { https://orcid.org/0000-0002-9578-4535 } \\ \text { Ji Hyun An } & \text { https://orcid.org/0000-0002-1628-9617 } \\ \text { Hye Rin Lee } & \text { https://orcid.org/0000-0001-8599-0231 } \\ \text { Seo Hyun Jeong } & \text { https://orcid.org/0000-0003-4390-0271 } \\ \text { Soo Jin Hwang } & \text { https://orcid.org/0000-0001-7426-1439 } \\ \text { Jin Pyo Hong } & \text { https://orcid.org/0000-0001-5384-2605 }\end{array}$

\section{REFERENCES}

1. House JS, Landis KR, Umberson D. Social relationships and health. Science 1988;241:540-545.

2. Xia N, Li H. Loneliness, social isolation, and cardiovascular health. Antioxid Redox Signal 2018;28:837-851.

3. Holt-Lunstad J, Smith TB, Layton JB. Social relationships and mortality risk: a meta-analytic review. PLoS Med 2010;7:e1000316.

4. de Jong Gierveld J, Havens B. Cross-national comparisons of social isolation and loneliness: introduction and overview. Can J Aging 2004; 23:109-113.

5. Cacioppo S, Grippo AJ, London S, Goossens L, Cacioppo JT. Loneliness: clinical import and interventions. Perspect Psychol Sci 2015;10: 238-249.

6. Victor CR, Scambler S, Bowling A, Bond J. The prevalence of, and risk factors for, loneliness in later life: a survey of older people in Great Britain. Ageing Soc 2005;25:357-375.

7. Savikko N, Routasalo P, Tilvis RS, Strandberg TE, Pitkala KH. Predictors and subjective causes of loneliness in an aged population. Arch Gerontol Geriatr 2005;41:223-233.

8. Kotian DB, Mathews M, Parsekar SS, Nair S, Binu VS, Subba SH. Factors associated with social isolation among the older people in India. J Geriatr Psychiatry Neurol 2018;31:271-278.

9. Taniguchi Y, Seino S, Nishi M, Tomine Y, Tanaka I, Yokoyama Y, et al. Physical, social, and psychological characteristics of community-dwelling elderly Japanese dog and cat owners. PLoS One 2018;13:e0206399.

10. Cotterell N, Buffel T, Phillipson C. Preventing social isolation in older people. Maturitas 2018;113:80-84.

11. Umberson D, Montez JK. Social relationships and health: a flashpoint for health policy. J Health Soc Behav 2010;51(Suppl):S54-S66.

12. Toepoel V. Ageing, leisure, and social connectedness: how could leisure help reduce social isolation of older people? Soc Indic Res 2013; 113:355-372.

13. Lucas K. Transport and social exclusion: where are we now? Transport Policy 2012;20:105-113.

14. Caspi A, Harrington H, Moffitt TE, Milne BJ, Poulton R. Socially isolated children 20 years later: risk of cardiovascular disease. Arch Pediatr Adolesc Med 2006;160:805-811.

15. Eaker ED, Pinsky J, Castelli WP. Myocardial infarction and coronary death among women: psychosocial predictors from a 20-year followup of women in the Framingham Study. Am J Epidemiol 1992;135: 854-864.

16. Shiovitz-Ezra S, Ayalon L. Situational versus chronic loneliness as risk factors for all-cause mortality. Int Psychogeriatr 2010;22:455-462.

17. Sugisawa H, Liang J, Liu X. Social networks, social support, and mortality among older people in Japan. J Gerontol 1994;49:S3-S13.

18. Valtorta NK, Kanaan M, Gilbody S, Ronzi S, Hanratty B. Loneliness and social isolation as risk factors for coronary heart disease and stroke: systematic review and meta-analysis of longitudinal observational studies. Heart 2016;102:1009-1016.

19. Hawkley LC, Thisted RA, Masi CM, Cacioppo JT. Loneliness predicts increased blood pressure: 5-year cross-lagged analyses in middle-aged and older adults. Psychol Aging 2010;25:132-141.
20. Hawkley LC, Cacioppo JT. Aging and loneliness: downhill quickly? Curr Dir Psychol Sci 2007;16:187-191.

21. Cacioppo JT, Hawkley LC, Thisted RA. Perceived social isolation makes me sad: 5-year cross-lagged analyses of loneliness and depressive symptomatology in the Chicago Health, Aging, and Social Relations Study. Psychol Aging 2010;25:453-463.

22. Prieto-Flores ME, Forjaz MJ, Fernandez-Mayoralas G, Rojo-Perez F, Martinez-Martin P. Factors associated with loneliness of noninstitutionalized and institutionalized older adults. J Aging Health 2011;23: 177-194.

23. Stickley A, Koyanagi A, Koposov R, Blatny M, Hrdlicka M, SchwabStone $\mathrm{M}$, et al. Loneliness and its association with psychological and somatic health problems among Czech, Russian and U.S. adolescents. BMC Psychiatry 2016;16:128.

24. Gale CR, Westbury L, Cooper C. Social isolation and loneliness as risk factors for the progression of frailty: the English Longitudinal Study of Ageing. Age Ageing 2018;47:392-397.

25. Cacioppo JT, Hawkley LC. Social isolation and health, with an emphasis on underlying mechanisms. Perspect Biol Med 2003;46:S39-S52.

26. Cacioppo JT, Hawkley LC, Berntson GG, Ernst JM, Gibbs AC, Stickgold R, et al. Do lonely days invade the nights? Potential social modulation of sleep efficiency. Psychol Sci 2002;13:384-387.

27. Calati R, Ferrari C, Brittner M, Oasi O, Olie E, Carvalho AF, et al. Suicidal thoughts and behaviors and social isolation: a narrative review of the literature. J Affect Disord 2019;245:653-667.

28. Leigh-Hunt N, Bagguley D, Bash K, Turner V, Turnbull S, Valtorta N, et al. An overview of systematic reviews on the public health consequences of social isolation and loneliness. Public Health 2017;152:157171.

29. Lubben JE. Assessing social networks among elderly populations. Fam Community Health 1988;11:42-52.

30. Lubben J, Blozik E, Gillmann G, Iliffe S, von Renteln Kruse W, Beck JC, et al. Performance of an abbreviated version of the Lubben Social Network Scale among three European community-dwelling older adult populations. Gerontologist 2006;46:503-513.

31. Lee KW, Kim SY, Chung W, Hwang GS, Hwang YW, Hwang IH. The validity and reliability of Korean version of Lubben Social Network Scale. Korean J Fam Med 2009;30:352.

32. Age UK. All the Lonely People: Loneliness in Later Life - Technical Report: presentation of analytical methodology and results. Available at: https://www.ageuk.org.uk/globalassets/age-uk/documents/reportsand-publications/reports-and-briefings/loneliness/180917_lonelinessreport-technical-report_final.pdf. Accessed November 1, 2020.

33. Dawson DA, Grant BF, Stinson FS, Zhou Y. Effectiveness of the derived Alcohol Use Disorders Identification Test (AUDIT-C) in screening for alcohol use disorders and risk drinking in the US general population. Alcohol Clin Exp Res 2005;29:844-854.

34. Han C, Jo SA, Kwak JH, Pae CU, Steffens D, Jo I, et al. Validation of the Patient Health Questionnaire-9 Korean version in the elderly population: the Ansan Geriatric study. Compr Psychiatry 2008;49:218-223.

35. Levis B, Benedetti A, Thombs BD; DEPRESsion Screening Data (DEPRESSD) Collaboration. Accuracy of Patient Health Questionnaire-9 (PHQ-9) for screening to detect major depression: individual participant data meta-analysis. BMJ 2019;365:11476.

36. Connor KM, Kobak KA, Churchill LE, Katzelnick D, Davidson JR. Mini-SPIN: a brief screening assessment for generalized social anxiety disorder. Depress Anxiety 2001;14:137-140.

37. Cho MJ, Hahm BJ, Suh DW, Hong JP, Bae JN, Kim JK, et al. Development of a Korean Version of the Composite International Diagnostic Interview (K-CIDI). J Korean Neuropsychiatr Assoc 2002;41:123-137.

38. Cantril H. Pattern of Human Concerns. New Brunswick, NJ: Rutgers University Press; 1965.

39. Ahn J, Kil H, Kim J, Kim J, Oh SJ, Jung SE. Work and Happiness (II). Sejong: Korea Labor Institute; 2016.

40. Caplan SE. Theory and measurement of generalized problematic In- 
ternet use: a two-step approach. Comput Hum Behav 2010;26:10891097.

41. Shimada K, Yamazaki S, Nakano K, Ngoma AM, Takahashi R, Yasumura S. Prevalence of social isolation in community-dwelling elderly by differences in household composition and related factors: from a social network perspective in urban Japan. J Aging Health 2014;26:807823.

42. Gene-Badia J, Comice P, Belchin A, Erdozain MA, Caliz L, Torres S, et al. [Profiles of loneliness and social isolation in urban population]. Aten Primaria 2020;52:224-232.

43. Steptoe A, Shankar A, Demakakos P, Wardle J. Social isolation, loneliness, and all-cause mortality in older men and women. Proc Natl Acad Sci U S A 2013;110:5797-5801.

44. Lee HG, Chung KJ. Social Isolation Condition Analysis: Among Busan, Ulsan, Gyeongnam Contact and Social Support in 2019: East South Area Statistics Korea. Busan: Statistics Korea; 2020.

45. Tanskanen J, Anttila T. A prospective study of social isolation, loneliness, and mortality in Finland. Am J Public Health 2016;106:20422048.

46. Brain B, Sally-Marie B. Isolation: the Emerging Crisis for Older Men: A Report Exploring Experiences of Social Isolation and Loneliness among Older Men in England. London: Independent Age; 2014.
47. Child ST, Lawton L. Loneliness and social isolation among young and late middle-age adults: associations with personal networks and social participation. Aging Ment Health 2019;23:196-204.

48. Statistical Research Institute. Korean Social Trends 2019. Daejeon: Statistical Research Institute; 2019.

49. Ejiri M, Kawai H, Fujiwara Y, Ihara K, Watanabe Y, Hirano H, et al. Social participation reduces isolation among Japanese older people in urban area: a 3-year longitudinal study. PLoS One 2019;14:e0222887.

50. Ge L, Yap CW, Ong R, Heng BH. Social isolation, loneliness and their relationships with depressive symptoms: a population-based study. PLoS One 2017;12:e0182145.

51. Beutel ME, Klein EM, Brahler E, Reiner I, Junger C, Michal M, et al. Loneliness in the general population: prevalence, determinants and relations to mental health. BMC Psychiatry 2017;17:97.

52. Stickley A, Koyanagi A. Loneliness, common mental disorders and suicidal behavior: findings from a general population survey. J Affect Disord 2016;197:81-87.

53. Park NS, Lee BS, Chiriboga DA, Chung S. Loneliness as a mediator in the relationship between social engagement and depressive symptoms: age differences among community-dwelling Korean adults. Health Soc Care Community 2019;27:706-716. 